\title{
AMPURIAS EN LA ANTIGÜEDAD TARDÍA. UNA NUEVA PERSPECTIVA
}

\author{
POR \\ J. M. NOLLA \\ Universitat de Girona
}

RESUMEN

La historiografia tradicional ha venido sosteniendo que durante la Baja Antigüedad la ciudad de Ampurias no era otra cosa que el fantasma apenas tangible de su lejana grandeza. Sin embargo, una lectura atenta de los datos y un conjunto de nuevas evidencias, textuales y arqueológicas, permiten plantear los hechos de manera bien distinta y reconocer, para esta etapa histórica, un periodo de gran importancia para la ciudad, sede episcopal y el puerto más activo de un vastisimo territorio.

\section{SUMMARY}

Traditional historiography has always maintained that during the Late Antiquity period, the city of Ampurias represented no more than a faint shadow of its former greatness. However, a careful reading of the data and a body of new evidence, both textual and archaeological, allow us to establish the facts in a very different way and to recognize that this stage in its history was a very important one for the city, which was an episcopal see and the most active port in a very vast territory.

Es mérito del gran erudito gerundense J. Botet i Sisó haber sistematizado los trazos generales de la evolución histórica de la ciudad de Ampurias. Precisamente, en la primera monografia científica y moderna sobre la vieja fundación focea, fijaba la decadencia urbana irremediable, a partir de datos documentales y arqueológicos, a raiz de la destrucción de la ciudad 
por parte de los invasores germánicos que a mediados del siglo tercero habrian asolado Hispania '. A partir de este momento, la historia posterior no era otra cosa que una lenta agonía hasta el abandono definitivo del lugar durante la Alta Edad Media con el desplazamiento de la capital condal hasta Castelló d'Empúries, a unos $17 \mathrm{~km}$. de distancia hacia el norte y más alejada del mar. Este esquema, sin apenas modificaciones, ha seguido vigente hasta, prácticamente, la actualidad, incorporado a las sintesis más recientes sin apenas discusión ?

Años más tarde, P. de Palol, profundo conocedor de la arqueología de estos territorios, enriqueció esta teoría con nuevos datos al relacionar Ampurias con el territorio circundante. En efecto, como consecuencia de sus trabajos en la Ciudadela de Rosas, en el Puig de les Muralles a Puig Rom (Rosas) y en la propia Ampurias ${ }^{3}$, apuntaba la posibilidad de relacionar la decadencia ampuritana con la consolidación y crecimiento de Rosas y, en general, de todo el sector norte del golfo, unas circunstancias que parecian repetirse diversas veces en el decurso de la historia, según las cuales parece que la expansión y el auge económico de Rosas coincide con la crisis y decadencia de su vecina Ampurias. Como si de unos vasos comunicantes se tratara, la presión hacia abajo de la vieja fundación jonia comportaba el esplendor de su pre-

' J. Botet y Sisó, Noticia histórica y arqueológica de la antigua ciudad de Emporion, Madrid, 1879 (Barcelona, 1979), 49-52 y 130-141. En contra de esta teoría que se basaba en buena parte en las evidencias arqueológicas, Madoz, que a partir de las fuentes históricas, intuye, tal como intentaremos probar nosotros a lo largo de este trabajo, que en realidad la ciudad vive en la Baja Antigüedad una larga etapa especialmente brillante como denotaría el haber sido una importante sede episcopal ( $\mathrm{P}$. Madoz, Diccionario geográfico-estadistico-histórico de España y sus posesiones de Ultramar, Madrid, II, 1845, 261).

2 Véase, por ejemplo, R. Font, Episcopológico ampuritano, precedido de una reseña histórica $y$ arqueológica de Ampurias, Gerona, sin fecha (1897), 53-73, donde estructura hábilmente y desarrolla los esquemas trazados por Botet, incidiendo sobre la destrucción de la ciudad que considera más probable fechar en el siglo v; M. Almagro, Ampurias, Historia de la ciudad y guia de las excavaciones, Barcelona, 1951, 49-55; idem, Las fuentes escritas referentes a Ampurias, Barcelona, 1951, (Monografias Ampuritanas, I), 97; idem, Las necrópolis de Ampurias. Vol. II. Necrópolis romanas y necrópolis indigenas, Barcelona, 1955, (Monografias Ampuritanas, III), 289; P. de Palol, Fíbulas y broches de cinturón de época visigoda en Catalunya, Archivo Español de Arqueologia, XXIII, 1950, 77; idem, Rosas. De la Antigüedad a la Edad Media, Revista de Gerona, 31, 1965, 25; idem, Arqueologia cristiana de la España romana (siglos $(V$-VI), Madrid/Valladolid, 1967, 30-31; J. Maluquer de Motes, Rhode, Rosas. La ciudad más antigua de Cataluña. (Un capitulo inédito de la historia catalana), Revista de Gerona, 31, 1965, 23; E. Ripoll, Ampurias. Descripción de las ruinas y museo monográfico, Barcelona, 1969, 17; M. Tarradell, Les ciutats romanes dels Països Catalans. Discurs llegit el dia 18 de maig de 1978 en l'acte de recepció pública de M. Tarradell i Mateu a la Reial Acadèmia de Bones Lletres de Barcelona i resposta de l'acadèmic numerari, Lluís Pericot i Garcia, Barcelona, 1978, 44; P. Bonnassie, Catalunya mil anys enrera (segles X-XI). I. Economia i societat pre-feudal, Barcelona, 1979, 99-100; A. Montenegro, La crisis del siglo in y la Hispania del Bajo Imperio en La conquista y la explotación económica, vol. I de España romana (218 a. de J. C.- 414 de J. C.) (Historia de España dirigida por J. M. Jover), Madrid, 1982, 251).

${ }^{3}$ Para los trabajos efectuados en Rosas (Ciudadela, villa de la Vinya d'en Guerra y Puig Rom), consultar: L. Pericot, J. M. Corominas, M. Oliva, F. Riuró y P. de Palol, La labor de la Comisaria Provincial de Excavaciones Arqueológicas de Gerona durante los años 1942 a 1948, Informes y Memorias, núm. 27, Madrid, 1952, 134-145, 159-161 y 163-182; P. de Palol, op. cit. (n. 2), 23-33. Sobre la actividad en Ampurias hay que consultar el valioso trabajo: M. Almagro y P. de Palol, Los restos arqueológicos paleocristianos y alto-medievales de Ampurias, Revista de Gerona, 20, 1962, 27-41. 
tendida rival ${ }^{4}$. Estas ideas que completaban el panorama y que ayudaban a explicar el proceso histórico de aquel territorio desde el Bajo Imperio, fueron asumidas, también, incorporándose rápidamente a estudios monográficos y de sintesis

Sin embargo, este esquema histórico presentaba ángulos oscuros, zonas muertas enormes que era preciso iluminar. Efectivamente, por un lado, a pesar de la supuesta destrucción de la ciudad por los bárbaros, quedaba claro que ésta no llegó a desaparecer si bien habria iniciado una larga etapa de decadencia y ruina, acelerada por otros muchos desastres (colmatación del puerto, saqueo normando, actividades piráticas,...) hasta el siglo XI o XII; por otro, era un hecho indiscutible que Ampurias habia sido sede episcopal documentada desde el año 516 fecha en que Paulo, obispo de la ciudad, firma los cánones del concilio provincial de Tarragona ${ }^{6}$ y desde este instante podemos rastrear la presencia de éste y otros obispos ampuritanos a lo largo de todo el siglo VI y vil hasta el 693 fecha en que Gaudila firmó en los cánones del XVI Concilio de Toledo'? Después no volveremos a tener noticias de esta sede episcopal por lo que hay que suponer que habría desaparecido con la invasión sarracena (hacia el 717) o durante los

4 P. de Palol, op. cit. (n. 2), 77-78; idem, Las mesas de altar paleocristianas en la Tarraconense, Ampurias, XIX-XX, 1957-1958, p. 88; idem, op. cit. (n. 2), 30-31 y 35; idem, op. cit. (n. 2), 25-26. Recientemente ha matizado estas consideraciones ( $\mathrm{P}$. de Palol, Del Baix Imperi a la presència dels àrabs, Jornades d'història de l'Empordà. Homenatge a Pella i Forgas, Gerona, 1987, 123-124. Esta propuesta es absolutamente razonable especialmente si se asumia como indiscutible la destrucción y ruina de Ampurias. Al lado de modestos hallazgos tardios en Ampurias, las excavaciones de la Ciudadela proporcionaban un material abundante y extraordinario $y$, además, el hecho de que la monarquía goda acuñe moneda en esta ciudad parecía ser un dato más a tener en cuenta. Sin embargo, Rosas no tendrá obispado o al menos no lo consolidará (ver nota 9 de este trabajo) y el haber acuñado monedas durante algunos pocos reinados no deja de ser interesante pero no parece tener demasiada importancia sobre todo si no viene acompañado por otras evidencias. Pero si analizamos con cuidado los datos que la investigación arqueológica ha ido reuniendo sobre la Rosas tardía veremos que todos juntos son escasos, y no permiten hacerse una idea de conjunto. Existe un gran edificio con una factoria de salazones cerca de la playa que se abandona durante la segunda mitad del siglo vi y es ocupado por un pequeño cementerio que se extiende ligeramente hacia el norte. Más allá, alrededor de la iglesia románica de Santa Maria, se ha excavado otra necrópolis, que parece más importante y que ocupa una notable extensión, con una probable cella memoriae que se localizaria inmediatamente por debajo del templo medieval. Parece haber, más al sur, restos estructurales tal vez bajo-imperiales pero que pronto serán ocupados por nuevas tumbas que hay que asociar a la necrópolis de Santa Maria. En otros puntos de la villa han aparecido, nuevamente, pequeños cementerios tardios (con tumbas de tegulae, de ánfora,...) y sin embargo la «ciudad» no aparece por ningún lado. ¿No se ha localizado, aún? ¿Se trata de una ciudad dispersa? Es pronto para poder contestar a estas preguntas pero los hechos no nos permiten ver una ciudad consolidada, floreciente, una alternativa económica a la vecina Ampurias sino algo intangible que aún no podemos valorar con justeza. Sobre todo ello F. J. Nieto, La Terra Sigillata Africana en el nordeste de la Tarraconense. Tesis doctoral, Universidad Autónoma de Barcelona, 1991 (que saldrá publicada en breve) y J. M. Nolla y N. M. Amich, Els origens del cristianisme y la Baixa Antiguitat al nord-est de Catalunya. Una aproximació (en prensa).

${ }^{5}$ Maluquer, op. cit. (n. 2), 23; M. Oliva, Arquitectura románica ampurdanesa. Santa María de Rosas, Revista de Gerona, 61, 1972, 10-13.

" "Paulus in Christi nomine episcopus inpuritanae civitatis subscripsi» (Concilios visigóticos e hispano-romanos, editados por J. Vives y la colaboración de T. Marín y G. Martínez, Barcelona/Madrid, 1963, 38).

7 "Gaudila emporitanus episcopus subscripsi» (J. Vives, op. cit. (n. 6), 518). 
años de dominio musulmán de este territorio que durará hasta el $785^{\circ}$. Más adelante, a pesar de los esfuerzos de los condes de Ampurias a lo largo de la Edad Media, Roma no aprobará su restitución a causa, muy probablemente, de las presiones de los obispos de Gerona y de los condes de Barcelona.

Este hecho, la existencia de una Ampurias sede episcopal, era dificil de encajar en el fresco histórico ofrecido por arquéologos e historiadores y, más aún, a sabiendas que la «esplendorosan Rosas, del otro lado del golfo, no tuvo obispo por estas mismas fechas y, por lo tanto, formaria parte del territorio administrado eclesiásticamente desde Ampurias".

No era fácil adecuar estos datos con el claro esquema dibujado por Botet y sus continuadores que, por otra parte, parecian confirmar día a día las excavaciones del lugar. Era obvio que no todas las viejas colonias y municipios romanos consolidaron una sede episcopal en la Baja Romanidad y que algunas, por las razones que fuera, desaparecieron como centros urbanos. Sin salir de este territorio, ciudades alto-imperiales bien documentadas «dejan de ser» en este período - $\operatorname{Rosas}^{10}$, Caldes de Malavella ${ }^{11}$, Blandae ${ }^{12}$, Iluro ${ }^{13}$, Baetulo ${ }^{14}$, Siga-

^ La conquista de Gerona por los carolingios es señalada por el Cronicón de Moissac ( «Eodem anno gerundenses homines Gerundam civitatem Carolo regi tradiderunt») y por los Anales de Barcelona ( (Gerundam civitatem homines tradiderunt regi Karolo»). Véase R. d'Abadal, El domini carolingi a Catalunya. Vol. I de La Catalunya carolingia, Barcelona, 1987, 75-92; N. M. Amich y J. M. Nolla, Girona goda i sarraïna. 476-785, Gerona, 1992, (Quaderns d'història de Girona), 80-81.

"Una cuestión interesante es la probable existencia de una sede episcopal en Rosas antes del siglo vi que habria desaparecido, por causas desconocidas, sin dejar, apenas, rastro. La posibilidad se basa en el hallazgo en una catacumba de Siracusa de una inscripción funeraria que menciona a «Auxentius hispanus patria ep (iscopus) Rotdon»" que, por lo que parece, no es probable que pueda referirse a otra ciudad que no sea la ampurdanesa. Véase, sobre ello: A. Ferrua, Nuovi studi nelle catacombe di Siracusa, Rivista di Archeologia Cristiana, 17, 1940, 447-449; J. Vives, Un obispo español del siglo v, desconocido, Analecta Sacra Tarraconensia, XVII, 1944, 204-205; J. M. Nolla y N. M. Amich, op. cit. (n. 4).

${ }^{10}$ Sobre el municipio de época flavia (municipium flavium Rhodinorum), G. Fabre, M. Mayer e I. Rodà, Inscriptions romaines de Catalogne. III. Gérone, Paris, 1991, 18; J. M. Nolla, Les ciutats romanes del nord-est de Catalunya. Els municipis d'època flàvia, Homenatge al professor Miquel Tarradell (en prensa).

"Aquae Calidae en la antigüedad y no Aquae Voconiae como se ha supuesto. Véase G. Fabre, M. e I. Rodà, op. cit. (n. 10), 18 y 33-36; J. M. Nolla, op. cit. (n. 10).

12 Blandae, asimilada sin problemas a Blanes, plantea enormes dificultades agravadas por la falta de hallazgos epigráficos. Citada por Plinio entre los oppida civium Romanorum al lado de Baetulo e Iluro (Nat. Hist., III, 22), por Pomponio Mela (II, 90, «Inde Tarraconem parva sunt oppida Blandae, Iluro, Baetulo, Barcino...» y por Ptolomeo (II, 18) en último lugar del litoral de los laietanos, no es mucha la información que han proporcionado las excavaciones y los diversos hallazgos [véase: $\mathrm{M}$. del V. Vilà, M. Genera, E. Huntingford y D. Molas, Aportaciones al conocimiento de la antigua Blandae, Pyrenae, 13-14, 1978, 211-151; M. del V. Vilà, La ciudad romana de Blandae (Carta arqueológica de la comarca de la Selva), Barcelona, 1983]. Una excelente interpretación a partir de los pocos datos proporcionados por la arqueología y que defiende la no consolidación de Blandae como ciudad, puede verse en: J. Aquilué, Las reformas augusteas y su repercusión en los asentamientos urbanos del nordeste peninsular, Arqueologia Espacial, 5. Coloquio sobre distribución y relaciones entre asentamientos, Teruel, 1984, 101-103.

${ }^{13}$ G. Fabre, M. Mayer e I. Rodà, Inscriptions romaines de Catalogne. I. Barcelone (sauf Barcino), París, 1984, 125-173.

14 J. Guitart, Baetulo. Topografia arqueológica. Urbanismo. Historia, Badalona, 1976: G. Fabre, M. Mayer e I. Rodà, op. cit. (n. 13), 175-200. 
rra $^{15}$, Iesso ${ }^{16}$, Aesso $^{17}$, Ivlia Livica ${ }^{18}$ - apareciendo, tan sólo una nueva, Urgellum, en el siglo vi ciudad episcopal, como lo serán también Ampurias, Gerona, Egara. Auso, Barcelona, Tarragona (sede metropolitana al menos desde el 418), Dertosa e Ilerda, los centros urbanos y los distritos territoriales de esta época.

Otro dato a considerar, tal vez valorado en menor medida por arqueólogos e historiadores pero también muy importante, era la capitalidad condal de Ampurias en la reorganización territorial de la Marca por obra de Carlomagno que hay que fechar inmediatamente después de la conquista de Barcelona. En este momento, el nordeste peninsular se divide en tres distritos gobernados por un comes: Gerunda, Bisuldunum y Ampurias "'."

Todo esto había sido captado por la mayoria de historiadores preocupados por estos hechos que habian intentado explicar satisfactoriamente y sin demasiado éxito, a pesar de aguzar el ingenio y de acabar recurriendo al tópico del prestigio del nombre de la ciudad y a la nobleza de su origen ${ }^{20}$.

Una serie de nuevas noticias y la interpretación justa de los datos arqueológicos y documentales existentes, tomados por ellos mismos, sin apriorismos y relacionándolos con lo que conocemos del territorio circundante, permiten dibujar un esquema nuevo, distinto, que consideramos mucho más ajustado y razonable y donde parece encajar mejor lo que sabemos.

Si contemplamos las evidencias a partir del resultado de las excavaciones arqueológicas del yacimiento ampuritano, detectaremos, efectivamente, un progresivo abandono de la Neápolis y de la "ciudad romana» a partir de época de Claudio después de observar un cierto estacamiento urbano desde el principado de Octavio ${ }^{21}$. Estos datos parecian confirmar claramente el esquema evolutivo propuesto y, a partir del último tercio del siglo tercero, después del despoblamiento total del área urbana situada más al sur y sudoeste del puerto, la vida se habría concentrado en Sant Martí, la antigua Palaiápolis de Estrabón ${ }^{22}$ (figura 1), un espacio mínimo donde sólo era posible imaginar una vida decadente y en continuo avance hacia el colapso

15 G. Fabre, M. Mayer e I. Rodà, op. cit. (n. 13), pág. 53-62.

to M. Tarradell, op. cit. (n. 2), 22 y 52-53; G. Fabre, M. Mayer e 1. Rodà, Inscriptions romuines de Catalogne. II. Lérida, París, 1985, $111-112$.

17 M. Tarradell, op. cit. (n. 2), 23 y 53; G. Fabre, M. Mayer e 1. Rodà, op. cit. (n, 16), 49-95.

${ }^{1}$ M. Tarradell, op. cit. (n. 2), 18; G. Fabre, M. Mayer e 1. Rodà, op. cit. (n. 10), 18 y 175-179.

19 Inmediatamente después de la conquista de Gerona y su territorio en el 785 , se crea un único condado con aquella ciudad como capital, la gran fortaleza de esta región frente a los musulmanes. Poco después de la ocupación de Barcelona, a principios del siglo $\mathrm{Ix}$, se reorganizan estas posesiones y se crean los nuevos condados entre los cuales está Ampurias. En el 813 se menciona especificamente a Irmingarius como conde de esta ciudad. Sobre este cargo y su evolución véase: R. d'Abadal, Dels visigots als catalans. I. La Hispània visigòtica i la Catalunva carolingia, Barcelona, 1969, 181-226.

20 Por ejemplo, M. Almagro, op. cit. (n. 2), 52: «La existencia de la sede episcopal que tuvo Ampurias en la época visigoda no denuncia un renacer nuevo de la población, sino que se basaria en viejas tradiciones cristianas, como ocurrió en otros sitios, dado el carácter tradicional de la Iglesia Católica»; E. Ripoll, op. cit. (n. 2), 17: «Sin embargo, debió continuarse una exigua vida urbana, y el hecho de tratarse de una urbe tan antigua justifica la existencia de una sede episcopal que se mantendrá hasta la invasión árabe en el siglo vilı y que quizá tiene raíces apostólicas.»

${ }^{21}$ Un estado de la cuestión en: J. M. Nolla, L’abandonament de la Neàpolis emporitana. Estat de la qüestió i noves dades, Miscel.lània Arqueològica a Josep M. Requesens, Tarragona, 1992, 83-89.

${ }^{22} \mathrm{III}, 4,8$. Véase el texto original y la traducción (de A. Garcia y Bellido) en M. Almagro, op. cit. (n. 2), 76-78. 
final. En otro lugar hemos insistido en la necesidad de interpretar los datos de otro modo a partir del conocimiento global de la historia ampuritana, viendo en la decadencia que, en efecto, existe y es muy grave, una crisis nacida de las circunstancias especiales que configuraron, en su momento, el extraordinario crecimiento de la ciudad en base a una actividad comercial y a unas circunstancias politicas muy concretas que determinarán una auténtica edad de oro para Ampurias entre principios del siglo 11 y el último tercio del siglo I a. C. ${ }^{23}$ Ya hemos hecho notar que, a causa de la gran riqueza que afluye a la ciudad, ésta crece, se embellece y se dota de monumentos públicos de coste y, a menudo, notables, pero da la sensación, a veces, de un crecimiento excesivo, no armónico, consecuencia de unos hechos muy precisos e irrepetibles y que ayudan a explicar con claridad el abandono rápido de diversas áreas, innecesarias, que era imposible conservar. La ciudad (o, mejor, las ciudades $\left.{ }^{24}\right)$ que creció vertiginosamente, decae, también, a la misma velocidad. Sus más de treinta hectáreas, una gran superficie para una fundación tardorrepublicana, resultan excesivas y empiezan a abandonarse casas y diversos sectores públicos. Hay una grave crisis demográfica ${ }^{25}$. Pensamos que todos estos datos son de un extraordinario valor para rastrear los efectos de la mutación sobre la ciudad y el camino

23 J. Aquilué, R. Mar, J. Nolla, J. Ruiz de Arbulo y E. Sanmartí, El förum romà d'Empúries. (Excavacions de l'any 1982). Una aproximació arqueològica al procés históric de la romanització al nordest de la Peninsula Ibèrica, Barcelona, 1984 (Monografies Emporitanes, VI), 135-141; J. Ruiz de Arbulo, Emporion-Emporiae (218 a. C. 100 d. C.), Tesis doctoral, Universidad de Barcelona, 1986, 302-403; J. M. Nolla, Empúries. Creixement, crisi i adaptació. Algunes consideracions, Jornades internacionals d'arqueologia romana. De les estructures indigenes a l'organització provincial romana de la Hispània Citerior. 1. Documents de Treball, Granollers, 1987, 291-297; J. Ruiz de Arbulo, Los inicios de la romanización en occidente: los casos de Emporion y Tárraco, Athenaeum, LXXIX, 1991, 459-490.

${ }^{24}$ En efecto, no olvidemos que desde finales del siglo ॥ a. C. hasta la segunda mitad del siglo I a. C. existen en Ampurias dos (o tal vez tres) ciudades yuxtapuestas. Véase J. Ruiz de Arbulo, op. cit. (n. 23), 302-476. Sobre las causas del desarrollo y crisis posterior, consúltese, además de la bibliografia citada en nota 25, los siguientes trabajos: F. J. Nieto y J. M. Nolla, El yacimiento arqueológico submarino de Riells-la Clota y su relación con Ampurias, VI Congreso Internacional de Arqueología Submarina, Cartagena, 1982 (Madrid, 1985), 265-283; J. Aquilué, R. Mar, J. M. Nolla, J. Ruiz de Arbulo y E. Sanmarti, op. cit. (n. 23) 135-143; J. Ruiz de Arbulo, op. cit. (n. 23), 400-417; J. M. Nolla, op. cit. (n. 23), 291-297; J. M. Nolla y F. J. Nieto, La importación de ánforas romanas en Cataluña durante el periodo tardo-republicano, Amphores romaines et histoire économique. Dix ans de recherche, Roma, 1989 (collection de l'École Française de Rome, 114), 367-391.

${ }_{25}$ Esta hipótesis fue planteada inicialmente por Ripoll y Martí a partir del análisis del material cerámico de una cisterna de la casa romana número 1 de Ampurias (E. Ripoll y F. Martí, Materiales cerámicos de una cisterna en Ampurias, Ampurias, XXX, 1968, 275-292). Después no han cesado de aportarse datos nuevos mucho más precisos (F. J. Nieto, Acerca del progresivo despoblamiento de Ampurias, Rivista di Studi Liguri, XLVII, 1983, 34-51, a partir del estudio de la cerámica africana). Tal vez pueda pensarse que las reformas flavias que afectan este territorio, con la creación del municipio de Rosas que se tuvo que hacer a partir de su propio ager (J. M. Nolla, op. cit. (n. 10)), tengan que ver con la crisis de la ciudad (Cf. J. Aquilué, op. cit. (n. 12), 95-113). Es interesante constatar que cuando Ampurias se dote de grandes edificios públicos de diversión - un anfiteatro y una palestra situados fuera muros - en la primera mitad del siglo i d. C. (M. Almagro, El anfiteatro y la palestra de Ampurias, Ampurias, XVII-XVIII, 1955-1956, 1-20), su construcción, muy sencilla, denota a las claras la decadencia de las clases dirigentes y, en última instancia, de la administración incapaz de hacer frente al coste que representaban estos edificios que vemos aparecer en estas fechas en la mayor parte de las ciudades. 


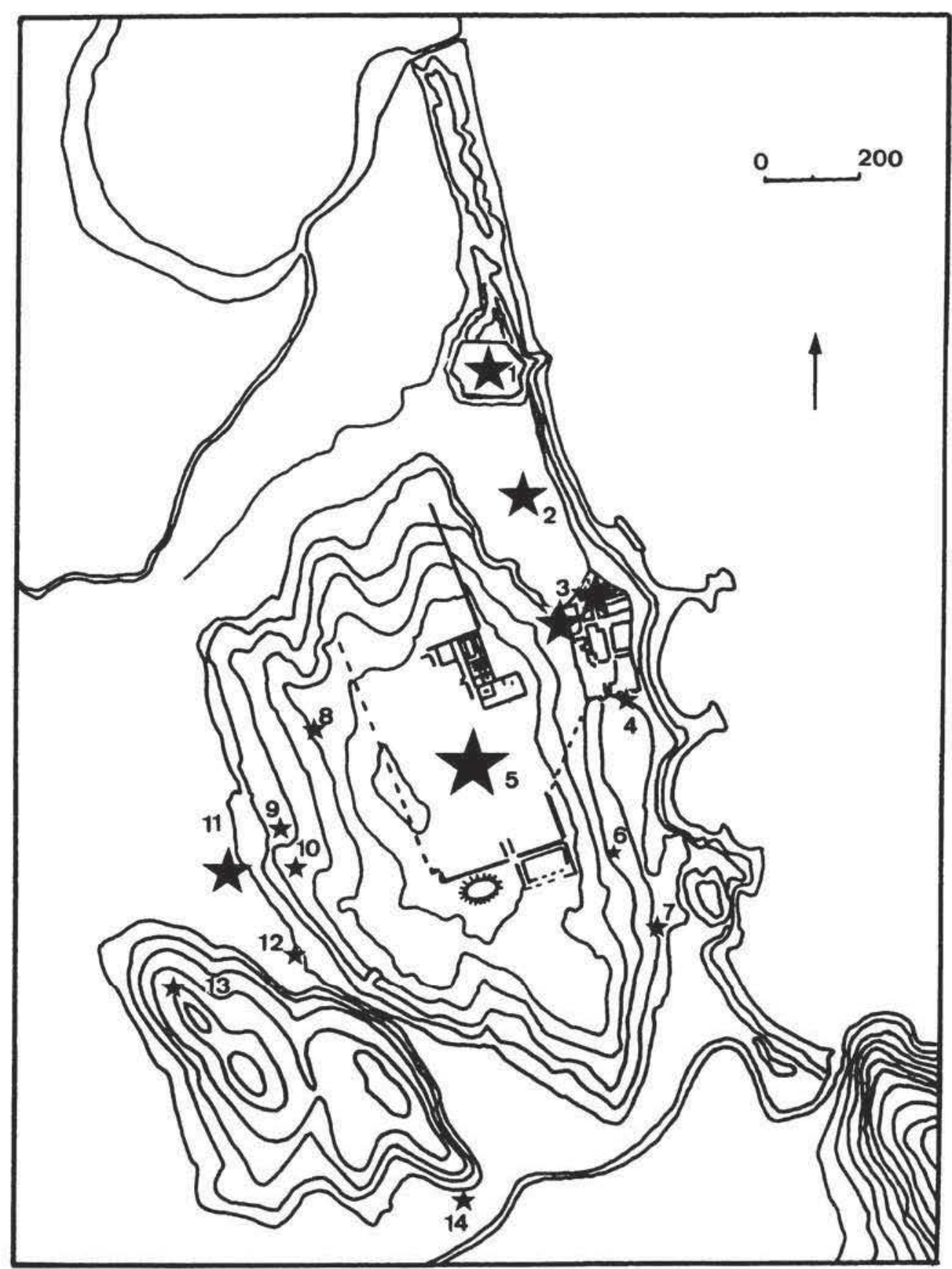

Figura 1.-Plano topográfico general del área de Ampurias. Al norte se distingue el curso y la desembocadura del Riuet, el brazo más meridional del rio Fluvià, que sigue, aproximadamente, el antiguo curso; 1. Sant Martí (Palaiápolis); 2. Antiguo puerto, al oeste, al pie del acantilado, circula el camino que conecta la Neápolis con Sant Martí; 3. Cementerio de la Neápolis; 4. Cementerio de la muralla meridional de la Neápolis; 5. "Ciudad romana»; 6. Necrópolis Bonjoan; 7. Necrópolis de «l'Hort de la Palanca»; 8. Necrópolis Rubert; 9. Necrópolis Nofre; 10. Necrópolis Estruc; 11. Santa Margarida;

12. Santa Magdalena; 13. El Castellet; 14. Sant Vicenç. 
hacia un nuevo equilibrio que pasará, inexorablemente, por echar por la borda todos los pesos muertos, enormes, absolutamente innecesarios, y adaptarse a una nueva situación muy distinta de la anterior. La Ampurias de la Tardia Antigüedad es, sobre todo, fortaleza y puerto, centro político de un territorio activo y equilibrado, pero donde no hay grandes espacios públicos, edificios de diversión ni nada parecido que recuerde la lejana época de la Baja República y primeros años del Imperio. Y sin embargo nada más es necesario. Un centro pequeño, bien protegido y dinámico y un territorio suburbano en ebullición son suficientes.

El punto álgido de esta crisis hay que fecharlo hacia el $270^{26}$, momento en que todo el sector meridional y occidental del puerto (Neápolis y «ciudad romana», con las áreas periféricas) se han abandonado completamente. La vida se habria concentrado en Sant Marti, la antigua isla, un espolón rocoso que se alza al norte del puerto (figura 1).

¿Significa este hecho el fin de Ampurias, tal como se pensaba, siguiendo a Botet? Nosotros pensamos que no, que tan sólo señala el momento final de la crisis y el hallazgo de un nuevo equilibrio al adaptarse a la nueva situación.

Tracemos brevemente las líneas maestras del devenir histórico de Ampurias a partir del Bajo Imperio y veamos cuáles son los datos que permiten esta interpretación.

Sant Martí, habitado permanentemente desde finales del siglo vil o inicios del vi a. C., con claras frecuentaciones anteriore ${ }^{27} \mathrm{y}$ donde es muy probable que se haya de situar el emplazamiento del templo de Artemis Efesia ${ }^{28}$, ofrece un lugar óptimo para acoger la pequeña ciudad que ha resultado de la larga y grave crisis; se halla sobre una pequeña elevación fácil de defender y bien protegida por el mar $\mathrm{y}$, además, permite controlar y aprovechar a la perfección el puerto y la desembocadura del Fluviá. Nada ha cambiado en relación al territorio de la ciudad con el que se conecta perfectamente. Estas circunstancias justifican la elección del lugar, más adecuado que el área de la Neápolis o que el sector más septentrional de la «ciudad romana», mucho más difíciles de defender y, en el caso del último lugar, mal comunicado con el puerto. Esta opción tiene, por lo demás, su lógica interna al no cambiar, en última instancia, el emplazamiento del pomerium, el solar sagrado, volviendo a concentrarse en el núcleo original. Era impensable el traslado a otro lugar, cerca o lejos, más allá de los límites sacralizados de la urbs (figura 1).

Sant Martí, en el Bajo Imperio, se dotará de unas poderosas murallas de opus quadratum con grandes sillares de piedra arenisca bien dispuestos que conocemos sólo parcialmente y que coinciden, por lo que sabemos, con las fortificaciones actuales y que podrían presentar alguna

26 F. J. Nieto, op. cit. (n. 25), 35-47; J. Aquilué, R. Mar, J. M. Nolla, J. Ruiz de Arbulo y E. Sanmarti, op. cit. (n. 23), 141-143 y 467-475; J. M. Nolla y J. Aquilué, Notes sobre una cassola de cuina de ceràmica africana procedent d'Empúries, Informació Arqueològica, 42, 1984, 51-57, con datos diversos y complementarios sobre el material cerámico más tardio. Las monedas más modernas localizadas en la "ciudad romana" corresponden al emperador Claudio 11 (268-270 d. C.) algunas de las cuales pueden ser algo más tardías al corresponder a la serie consecratio en el reverso. Véase S. J. Keay, Annex 8. Les monedes de l'excavació de 1982 a Empúries en J. Aquilué, R. Mar, J. M. Nolla, J. Ruiz de Arbulo y E. Sanmarti, op. cit. (n. 23), 479-492.

27 J. Rovira y E. Sanmarti, Els orígens de l'Empúries precolonial i colonial, Informació Arqueològica, 40, 1983, 95-110.

${ }^{2 x}$ III, 4, 8. Texto original y traducción (de A. García y Bellido) en M. Almagro, op. cit. (n. 2), 77-78. 


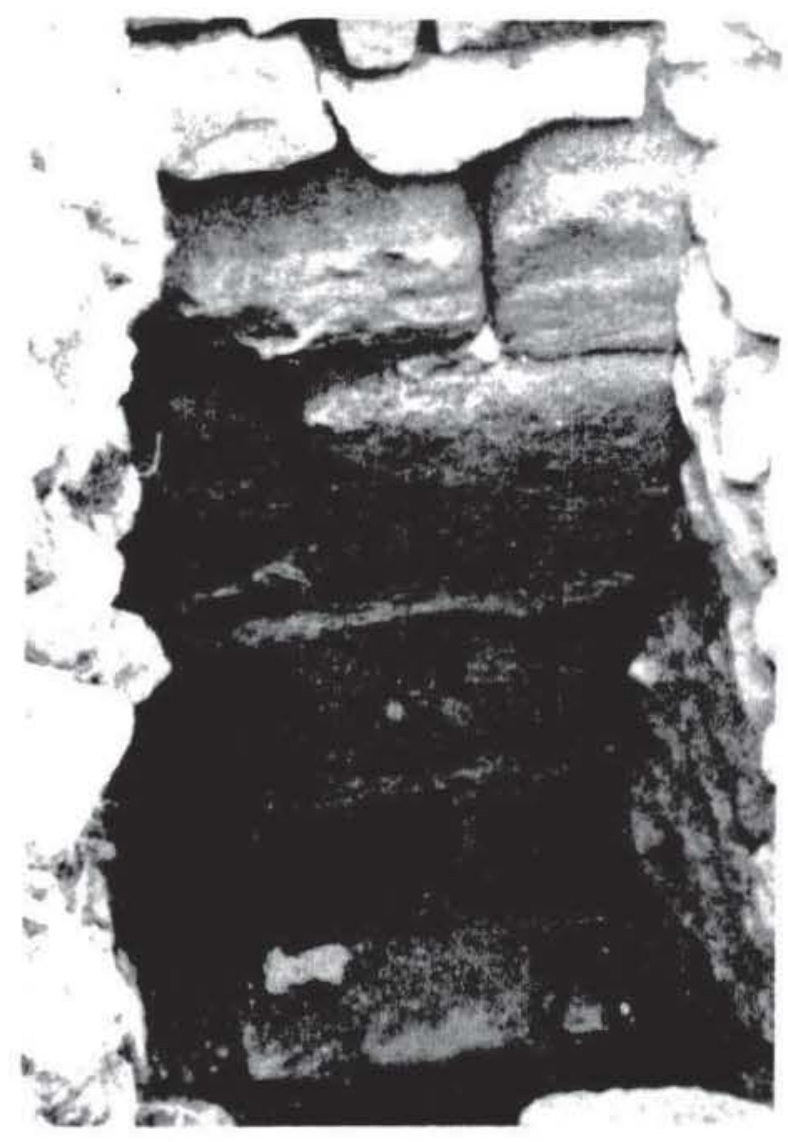

Figura 2. Cara interna de la muralla bajo-imperial de Sant Marti. con los grandes sillares de piedra arenisea. Sector oriental. al norte de la iglesia.

torre de planta cuadrangular. Se trata de la mal llamada, por Almagro, «muralla helenistica» " (figura 2) que las excavaciones, inéditas, de 1975 permiten asegurar que son tardorromanas. La datación justa no es posible si bien Keay ha propuesto a través del análisis de los datos de los sondeos más modernos, una cronologia del siglo v ${ }^{30}$ que es verosimil y que coincidiria con la nueva datación propuesta para las fortificaciones tardias de Barcino". El aspecto formal recuerda extraordinariamente el de las murallas bajo-imperiales de Geranda que hay que fechar, sin dudas, muy a finales del siglo tereero ${ }^{12}$. Fn uno u otro caso lo que si es cierto es que

20 M. Almagro, Excavaciones en la Palaiapolis de Ampurias. Fxcavaciones Arqueológicas en España, 27. Madrid, 1964, 8 y 97-98, lams. XLV, XLVI. 1, 2 y L. 3 y 4 y planos generales.

3i) S. J. Keay, Late Roman amphorae in the Western Mediterrancan. A spologrc and economic study: the Catalan evidence, Oxford, 1984 (BAR International Series, 196), 6-9.

" R. Jarrega, Consideraciones sobre la cronologia de las murallas tardorromanas de Barcelona: ¿una fortificación del siglo $\mathrm{V}$ ?, AEsp A, 64, 1991, 326-335.

12 J. M. Nolla y F. J. Nieto, Acerca de la cronologia de la muralla tardia de Gerunda: la Terra Sigillata Clara de "Casa Pastors», Faventia, 1/2, 1979, 265-283; J. M. Nolla, Gerunda: dels origens a la li del món antic, Fonaments, 7, 1988, 85-88 y 106. 
durante la Baja Antigüedad, Sant Marti, la urhs ampuritana, se protegió con sólidas obras de fortificación que resultarán una excelente inversión de futuro.

Del interior de la ciudad sabemos poco. Las excavaciones con éxito se han centrado en un solar al norte de la iglesia con el hallazgo de un cementerio y obras de defensa medievales y restos de habitaciones tardorromanas pertenecientes a un edificio indeterminado y algunas tumbas en ánfora que sirven para detectar la más antigua necrópolis intra muros ${ }^{33}$. Dentro de la iglesia se conserva una mesa de altar paleocristiana que se ha fechado en los siglos iv $\mathrm{y} \mathrm{v}^{34}$ que puede suponerse procedente de un templo del lugar (en torno al cual se habria desarrollado el cementerio tardorromano aludido) y una cantidad notable de material arqueológico que permite seguir la continuidad de la ocupación de este lugar desde el siglo IV al VII ${ }^{35}$. Interesa señalar, también, la existencia documentada de la iglesia consagrada al santo confesor de Tours ya en el 843 , una fecha muy antigua que nos hace pensar en la posibilidad de que se tratara del templo catedralicio de época visigoda ${ }^{36}$ (figura 1).

Tenemos otros muchos datos en relación al territorio inmediato que hay que conocer, juntar y calibrar, para ver el valor real que poseen. Inmediatamente al sur, al otro lado del puerto, ocupando una vasta extensión, se localiza una enorme necrópolis, el gran cementerio de Sant Martí entre los siglos IV y vill, que poseerá una cella memoriae y que contaba, como minimo, con 500 tumbas ${ }^{37}$ (figura 1). De allí proceden dos interesantes sarcófagos esculturados de taller romano que se fechan entre finales del siglo tercero y principios del cuarto ${ }^{38}$, que son elementos a tener en cuenta como prueba de la existencia de la ciudad y de sus contactos con el exterior en aquellas fechas y de una aristocracia urbana capaz de importar objetos de lujo de

${ }_{33}$ S. J. Keay, op. cit. (n. 30), 8-9; J. M. Nolla y N. M. Amich, op. cit. (n. 4).

${ }^{34}$ P. de Palol, op. cit. (n. 2), 187; S. Alavedra, Les ares d'altar de Sant Pere de Tarrasa. Egara. Vol. II. Inventari de les ares, Terrassa, 1979, 123-126 (núm. 27); J. M. Nolla y N. M. Amich, op. cit. (n. 4).

is M. Almagro, op. cit. (n. 29), 32-85, especialmente; F. J. Nieto, op. cit. (n. 25), 49-51, cuadro XIII; S. J. Keay, op. cit. (n. 30), 5-9.

36 ...et per reliquias Sancti Martini confessoris cuius basilica sita esse dignoscitur infra muros Empurias civitate, supra cuius sacrosanto altario has conditiones manibus nostris continemus... (Cartoral de Carlomagno, Archivo Episcopal de Gerona. Véase la transcripción completa en M. Almagro, op. cit. (n. 2), 125-127. El documento es de un interés extraordinario puesto que nos menciona el templo dedicado al santo de Tours donde se guardaban unas reliquias todo ello «infra muros Empurias civitate». ¿Se trata de un viejo templo o de un edificio carolingio? A menudo se ha considerado que la expansión de este culto, tan popular en Cataluña, viene unida a la penetración franca y, mayoritariamente, asi debe ser. Sin embargo el prestigio de Martín, el enorme desarrollo de su culto inmediatamente después de su muerte y las intensas relaciones de Hispania y Gallia en el Bajo Imperio nos hacen ir con cuidado. No sería de extrañar que la advocación al santo confesor fuera en este caso anterior a la conquista sarracena. Sobre el culto a San Martín en la Tardia Antigüedad, tan extendido en estas latitudes, consúltese C. Garcia Rodriguez, El culto de los santos en la España romana y visigoda, Madrid, $1966,336-342$.

${ }^{37}$ Un nuevo análisis de este cementerio en: J. M. Nolla y N. M. Amich, op. cit. (n. 4); J. M. Nolla, Els cementiris de la Neàpolis emporitana, Reunió d'Arqueologia Paleocristiana Hispànica, Lisboa, 1992 (en prensa).

${ }^{38}$ J. Botet y Sisó, op. cit. (n. 1), 118-122; A. García y Bellido, Esculturas romanas de España y Portugal, Madrid, 1949, 267-274 (piezas números 271 y 272); G. Bovini, I sarcofagi paleocristiani dalla Spagna, Ciudad del Vaticano, 1954, 25; M. Almagro y P. de Palol, op. cit. (n. 3), 31-33; J. M. Nolla y N. M. Amich, op. cit. (n. 4). 
la lejana capital ${ }^{30}$. Es un cementerio bien organizado que, en un momento avanzado, se delimita con un muro por el sector meridional y donde se construirán unas escaleras y una rampa para acceder del nivel de circulación al nivel basilical y con aulas funerarias de un notable interés ${ }^{40}$. Más hacia mediodía, al otro lado de la muralla de la Neápolis, se halla otra necrópolis, menor pero muy interesante, con dos momentos de uso - finales del siglo $1 /$ inicios del siglo " y Antigüedad Tardía - que no puede relacionarse, en modo alguno, con la necrópolis neapolitana ${ }^{+1}$ (figura 1).

Un repaso crítico a la publicación de $\mathrm{M}$. Almagro dedicada a las necrópolis ampuritanas basta para darse cuenta del significado de los cementerios tardios en relación a los alto y medio imperiales (siglos I a III) aún sin haber tratado el más extenso (Ncápolis). Hay tumbas tardias (de tegulae, de ánfora...) dispersas en la mayor parte de cementerios ${ }^{42}$ y necrópolis importantes como el Castellet o Ca l'Estruc (figura 1) que han proporcionado 28 y 59 inhumaciones, respectivamente ${ }^{43}$, que, en ningún caso, fueron exploradas completamente tal como

${ }^{39}$ A partir de un nuevo análisis de los restos estructurales de la cella memoriae dentro del marco global del gran cementerio tardio del sector norte de la Neápolis y áreas adyacentes, hemos llegado a la conclusión, con una serie de evidencias suficientes, que el excelente sarcófago romano llamado de «las estaciones», de muy principios del siglo IV, muy bien conservado y con la cubierta original intacta y frontalmente decorada, es la tumba principal, situada en el sanctuarium, simétricamente dispuesta frente al prebisterio y sobre la cual se alzaba la mensa altaris. Hay que suponer que en este sarcófago yacia un personaje muy importante del primer cristianismo ampuritano que al morir fue enterrado en este magnifico sarcófago de temática aún pagana pero que puede tener, sin dificultades, una lectura cristiana (Buen Pastor, las estaciones, el paso del año, ...). El lugar donde se depositó la tumba inicialmente nos es desconocido pero es probable que ya se tratara de un sector indeterminado de la necrópolis Marti, el área más occidental del gran cementerio neapolitano y donde se localizaron las inhumaciones más antiguas de, como muy tarde, principios del siglo Iv. Más adelante, la tumba habria sido trasladada al construirse el pequeño templo que aprovechó estructuras anteriores y a su alrededor se habrian ido depositando las sepulturas más notables. Se trataria, por lo tanto, de un cementerio ad sanctum, tal como pasa en muchos otros lugares, organizado alrededor del prestigio de alguien, mártir o no, de recuerdo imborrable para aquella comunidad naciente. Lamentablemente su memoria no ha dejado otros rastros que no sean arqueológicos.

40 J. Puig i Cadafalch, A. de Falguera y J. Goday, L'arquitectura románica a Catalunya. Vol. I. Precedents: l'arquitectura romana; l'arquitectura cristiana pre-románica, Barcelona, 1909, 266 y 268 272; M. Almagro, op. cit. (n. 2), 111-114; M. Almagro y P. de Palol, op. cit. (n. 3), 28-33; P. de Palol, op. cit. (n. 2), 32-37; J. Fontaine, El Prerrománico, Madrid, 1978, 425; H. Schlunk y T. Hauschild, Hispania Antiqua. Die Denkmäler der frühchristlichen und Westgotischen Zeit, Mainz, 1978, 161-162; X. Barral, L'art pre-romànic a Catalunya (segles $I X-X)$, Barcelona, 1981, 65 y 67; E. Junyent, $L$ 'arquitectura religiosa a Catalunya abans del romànic, Barcelona, 1983. 33-37; J. M. Nolla y N. M. Amich,op. cit. (n. 4).

41 J. M. Nolla y N. M. Amich, op. cit. (n. 4); J. M. Nolla, op. cit. (n. 37).

${ }^{42}$ Por ejemplo, en la necrópolis Rubert con 28 inhumaciones tardías: M. Almagro, op. cit. (n. 2), 19-22, 44 y 114-116; la Nofre, dos tumbas tardias que habria que unir al cementerio Estruc: M. Almagro, op. cit. (n. 2), 211; la Pi, con 10 inhumaciones de esta cronologia: M. Almagro, op. cit. (n. 2), $215-$ 223 y 227-232 y Bonjoan, con cuatro tumbas tardias: M. Almagro, op. cit. (n. 2), 284-286; idem, Las necrópolis de Ampurias. Vol. I. Introducción y necrópolis griegas, Barcelona, 1953 (Monografías Ampuritanas, III), 154. Sobre todo esto véase también: J. M. Nolla y N. M. Amich, op. cit. (n. 4).

${ }^{43}$ Sobre el Castellet; M. Almagro, op. cit. (n. 2), 289-304; sobre Ca I'Estruc; M. Almagro, op. cit. (n. 2), 305-320. 
indicó su excavador ${ }^{44}$. Hay que añadir a estos datos los hallazgos, dificiles de valorar, de las fases antiguas y las tumbas de la iglesia medieval de Santa Magdalena ${ }^{\text {t5 }}$ (figura 1) o de Sant Vicenç mucho más dudosas ${ }^{\text {th }}$ (figura 1 ) o la nueva necrópolis de l'Hort de la Palanca ${ }^{47}$ (figura 1) con enterramientos en ánforas de los siglos $\mathrm{v} y \mathrm{vi}^{4 \mathrm{x}}$, para empezar a dilucidar un panorama bien distinto. Además, la existencia de estas necrópolis y tumbas diseminadas por una extensa superficie, a lo largo de la falda occidental del altozano de la "ciudad romana" y en el "Turo de les Corts», especialmente, lejos del mar e invisible desde allí, nos inducen a imaginar la existencia de una población dispersa, suburbana, puesto que era absurdo suponer que estas tumbas pertenecieran a los habitantes del núcleo urbano de Sant Martí que poseían su propio cementerio (Neápolis) al otro lado del puerto y cómodamente comunicado por tierra ${ }^{49}$.

Otro dato importante procedía de las excavaciones de la iglesia románica de Santa Margarida, en el sector occidental del altozano de Ampurias, más allá (oeste) de la carretera que conduce a Sant Martí (figuras 1 y 3), y donde se localizaron los restos de un probable baptisterio anterior al templo medieval y que abría importantes interrogantes sobre el lugar durante la Tardia Antigüedad ${ }^{50}$.

La fotografia aérea y unas interesantes excavaciones de salvamento han servido para aportar nuevos datos, de gran valor, para el conocimiento de esta área durante la Baja Romanidad, datos que ayudan a comprender la extensión e importancia de la necrópolis Estruc (figura 1). Es mérito del doctor J. Casas haber localizado a partir del análisis de unas fotos

${ }_{44}^{4}$ M. Almagro, op. cit. (n. 2), 293-294 y 305.

45 M. Almagro y P. de Palol, op. cit. (n. 3), 39.

to M. Almagro y P. de Palol, op. cit. (n. 3), 34-36; J. Badia, L'arquitectura medieval de l'Empordà. II A. L'Alt Empordà, Gerona, 1978, 149-150; X. Barral, op. cit. (n. 40), 202.

47 J. M. Nolla y N. M. Amich, op. cit. (n. 4).

4k Ánforas de la forma Keay LXII que deben fecharse entre el segundo tercio del siglo $\vee$ y finales del siglo vi o inicios del viı. Señalemos como dato interesante la presencia de algún ejemplar de esta forma entre el material cerámico de las excavaciones del Puig de les Muralles (Puig Rom, Rosas) que por mucho que retrasemos su cronologia es un dato más a tener en cuenta si pretendemos avanzar la fecha fundacional del poblado al menos hasta finales del siglo vi o, si se quiere, muy a principios de la centuria siguiente, con lo cual su existencia se habría prolongado a lo largo de unos $130 / 150$ años.

${ }^{49}$ En efecto, todas estas necrópolis se hallan muy alejadas de Sant Marti $-\mathrm{y}$ a ellas hay que asociar, por lo que parece, los dos interesantes frontales de sarcófagos de mármol pirenaico y taller aquitano de procedencia ampuritana (P. de Palol, op. cit. (n. 2), 317-318) uno de los cuales, decorado con una triple corona, el crismón y el alfa/omega, procede, precisamente, del mismo campo donde se ha localizado el gran yacimiento tardío de Santa Margarida (J. Pella y Forgas, Historia del Ampurdán, Barcelona, 1883, 274 y plano entre página 202-203, letras E y f) - y hay que pensar, para cada sector concreto, un hábitat situado relativamente cerca, tal como hemos podido constatar con el gran edificio de Santa Margarida al que cabria atribuir los cementerios de Ca n'Estruc, Santa Magdalena y las tumbas dispersas de la necrópolis Rubert.

En cambio, a través de un viejo camino que se sitúa entre el puerto ampuritano y el acantilado que delimita por el este la "ciudad romana», es fácil y rápido desplazarse hasta el área cementerial. De hecho, no hay alrededor de Sant Marti otro lugar que ofrezca mejores condiciones y que se halle más cerca que la zona norte de la Neápolis.

50 M. Almagro y P. de Palol, op. cit. (n. 3), 37-39; P. de Palol, op. cit. (n. 2), 154-155; J. M. Nolla y N. M. Amich, op. cit. 


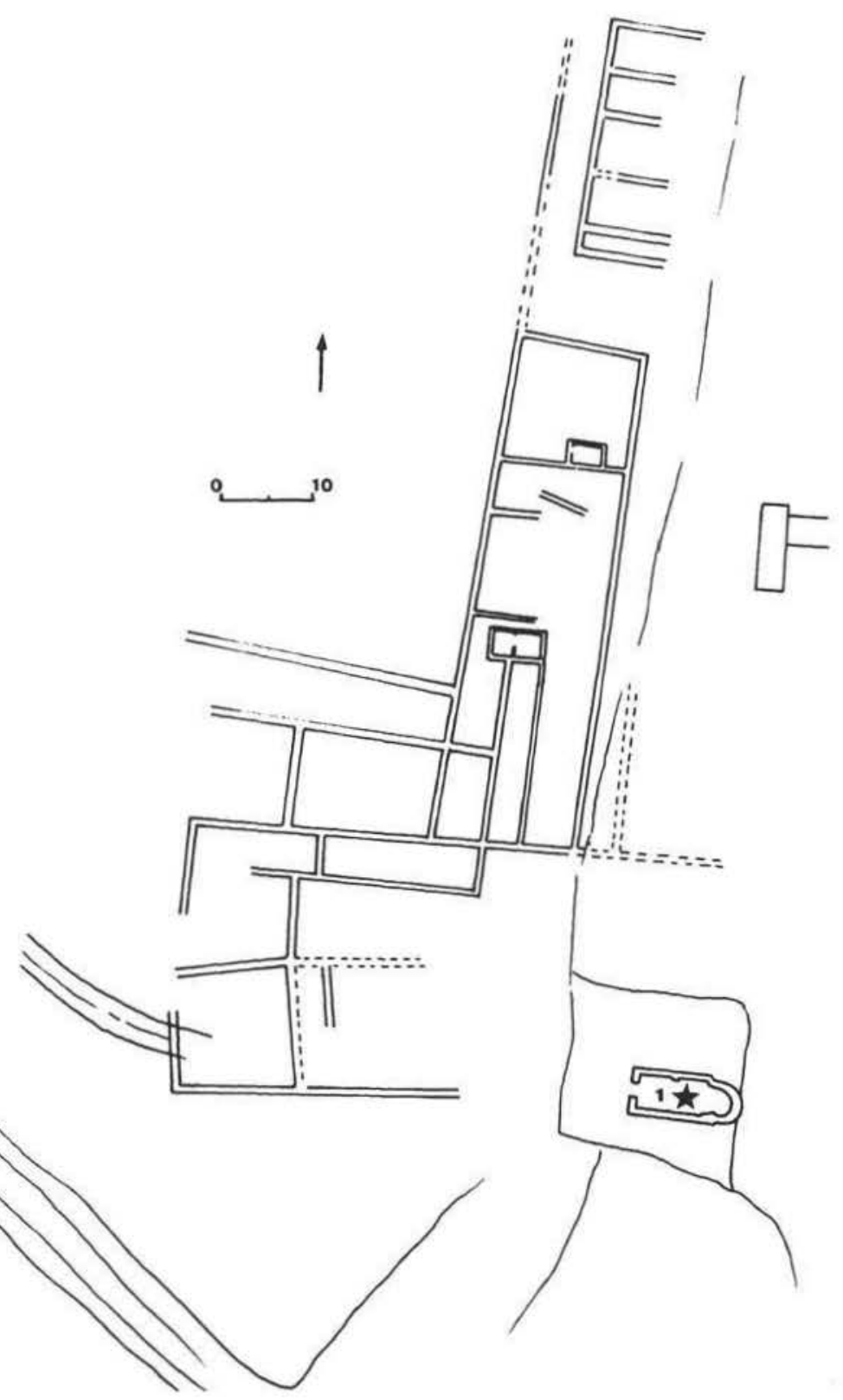

Figura 3.- Planta de las estructuras visibles del edificio de Santa Margarida restituido a partir de la fotografia aérea (según Josep Casas). 1.-Iglesia románica de Santa Margarida. E. 1:100.

aéreas ${ }^{51}$, un extensísimo edificio, dentro del cual se sitúa la pequeña iglesia de Santa Margarida (y por lo tanto las estructuras anteriores que ahora habrian de interpretarse en relación a esta

st Damos las gracias al amigo J. Casas, por la noticia y la restitución en planta, a partir de la foto aérea, del edificio y caminos del conjunto de Santa Margarida. El cliché fue tomado en mayo de 1982 en un vuelo vertical a baja altura que tenía como objetivo cubrir fotográficamente el conjunto monumental y áreas adyacentes de cara a restituciones planimétricas y encargado por la Diputación de Barcelona propietaria del yacimiento. 
gran construcción), con una serie de caminos fósiles que conducen a su interior desde el oeste o desde el sur y sureste. Son estructuras complejas que delimitan grandes habitaciones, patios y dependencias varias y que ocupan, a primera vista y muy aproximadamente, unos 6000 metros cuadrados de superficie. Este núcleo continuaba, claramente, hacia levante, hacia la carretera y las últimas pendientes de la colina ampuritana, muy cerca ya del cementerio de $\mathrm{Ca}$ l'Estruc y de otras tumbas tardias dispersas a su alrededor (figura 3). En seguida, por la proximidad de estas inhumaciones y por los hallazgos de Santa Margarida, propusimos, como hipótesis razonable, una cronología tardía para el edificio que diversas prospecciones visuales parecian confirmar pero que los trabajos de salvamento de octubre de 1991/enero de 1992 han probado plenamente ${ }^{52}$.

Por las características estructurales asemeja una gran villa suburbana pero la posibilidad de asociar al hallazgo el probable baptisterio descubierto por $\mathrm{P}$. de Palol en los años cincuenta ${ }^{53}$ nos hacen pensar en la posibilidad de localizar, en este sitio, la basílica y el palacio episcopal ${ }^{54}$ o un monasterio del cual tendriamos, tal vez, una referencia en el nombre de Secorius que firmó los cánones del XIII Concilio toledano como abbas en representación del obispo ${ }^{55}$. Son hipótesis llenas de sentido y que tan sólo una excavación extensiva del lugar permitirá solucionar convenientemente.

Algo parecido hay que suponer en relación al cementerio del Castellet, una extensa necró-

52 Véase un avance de estos resultados en X. Rocas, S. Manzano y A. M. Puig, L'excavació d'urgència a la carretera de Sant Marti d'Empúries a la carretera d'Orriols a l'Escala, Primeres Jornades d'Arqueologia de les Comarques de Girona, Sant Feliu de Guixols, 1992, 125-136; J. Llinàs, S. Manzano, A. Puig y X. Rocas, Noves aportacions al coneixement de les necròpolis emporitanes. I. Les troballes realitzades en l'excavació d'urgència a la carretera de Sant Martí d'Empúries, Annals de l'Institut d'Estudis Empordanesos, 25, 1992, 351-381.

${ }^{53}$ Véase nota 49.

${ }^{54}$ Esta cuestión ha interesado a todos aquéllos que se han preocupado por la Ampurias tardoantigua. Desde la suposición de que la iglesia catedralicia correspondia a la pequeña cella memoriae del cementerio neapolitano hasta la creencia de que iglesia y palacio episcopal se hallaban dentro de Sant Martí por debajo del templo gótico actual o en algún lugar no excavada del área de la antigua "ciudad romana" (véase J. M. Nolla y N. M. Amich, op. cit. (n. 4), donde se recogen estas diferentes propuestas). Nosotros hemos sostenido que el núcleo episcopal hay que buscarlo en la ciudadela fortificada de Sant Martí. Apoyarían esta suposición el ara paleocristiana, la solidez del recinto y su seguridad, la situación dominante de la actual iglesia que podría corresponder al emplazamiento de un viejo templo griego, la continuidad bien documentada de los lugares de culto, el viejo cementerio con tumbas en ánfora al lado mismo de la iglesia actual y la existencia segura, desde muy antiguo, de una basílica en este lugar (ver nota 35). Sin embargo, el gran edificio tardio de Santa Margarida, dentro de la cual hay que localizar el baptisterio descubierto y excavado por P. de Palol, nos obligan a mostrarnos cautos. Es probable que aquella gran construcción corresponda al conjunto episcopal, en este caso, a escasa distancia de la ciudad, separada y resguardada visualmente del mar. No olvidemos el hallazgo, en este lugar, de un sarcófago decorado de taller aquitano (ver nota 49 de este trabajo). Hay que relacionar también, este edificio con los cementerios del sector occidental de la colina de la "ciudad romana", situados inmediatamente delante, y con una lápida cristiana descubierta en 1896 y depositada en el museo diocesano de Gerona (R. Font, op. cit. (n. 2), 31, nota 2). Se trata de una sencilla inscripción sepulcral dedicada a Máximo (o Máxima), con un crismón con el alfa y la omega (G. Fabre, M. Mayer e I. Rodà, op. cit. (n. 10), 156-157, núm. 164). Es algo que hay que tener presente y que sólo podrán resolver las excavaciones futuras.

ss "Secorius abba Gaudilani Impuritani episcopi similiter» (J. Vives, op. cit. (n. 6), 433). 
polis delimitada por sus cuatro costados por un muro de obra de notable calidad ${ }^{56}$, que se localiza en el Turó de les Corts y que sólo se explica correctamente suponiendo la existencia de un hábitat no descubierto, y lo mismo pasa con cualquiera de los otros cementerios dispersos por el territorio inmediato a la ciudad.

Citemos, también, varios hallazgos epigráficos tardíos, con dos inscripciones funerarias de procedencia incierta ${ }^{57}$, y otra, conmemorativa, relativa a la consagración de unos altares dedicados al Protomártir y a una santa, que constituyen un documento importante de la historia de la Ampurias cristiana ${ }^{58}$, datos, todos ellos, únicos para el nordeste catalán, sin parangón en Rosas ni en la misma Gerunda. Señalemos, finalmente, una mensa altaris de mármol de Luni, de la cella memoriae de la Neápolis ${ }^{50}$, dos interesantes frontales de sarcófago decorados y de taller aquitano que hay que relacionar con las necrópolis periféricas y no con el gran cementerio neapolitano (figura $4 \mathrm{a} \mathrm{y} \mathrm{b)} \mathrm{y} \mathrm{un} \mathrm{soporte} \mathrm{de} \mathrm{altar,} \mathrm{de} \mathrm{mármol} \mathrm{blanco,} \mathrm{bellamente} \mathrm{decorado}$ por tres de sus cuatro caras que podría proceder de Sant Marti y que hay que fechar, sin duda, en pleno siglo $\mathrm{V}_{11}{ }^{60}$ (figura $5 \mathrm{a}, \mathrm{b}, \mathrm{c}$ y d).

El resultado es, pues, bien distinto del que presentaba la historiografia tradicional, con un núcleo central fortificado, defendiendo y en función de un puerto activo e importante, y de un área suburbana densamente ocupada, dinámica y activa, lejos de la imagen de desolación y desierto tan asimilada.

Con esta reinterpretación de los hechos, nosotros damos una gran importancia al puerto (o puertos ${ }^{61}$ ) de la ciudad, que continúa en activo y sugerimos, por su situación, tradición y dinamismo, que sea considerado como el principal del nordeste, más allá de Barcelona, y lugar por el que arriban los productos mediterráneos y por donde sale el excedente; un puerto menor,

${ }^{56}$ M. Almagro, op. cit. (n. 2), 289-304; J. M. Nolla y N. M. Amich, op. cit. (n. 4).

${ }^{57}$ G. Fabre, M. Mayer e I. Rodà, op. cit. (n. 10), 156-157, números 164 y 165.

${ }^{58}$ G. Fabre, M. Mayer e I. Rodà, op. cit. (n. 10), 155-156, núm. 163, donde se menciona un altar consagrado a San Esteban, el protomártir cuyas reliquias llegaron muy pronto a Hispania, a principios del siglo v, traidas por Orosio, y otro a Santa Aurea o Aurelia, mucho más probable la primera, mártir de Ostia y en cuya basilica, levantada en esta ciudad, fue enterrada Santa Mónica, madre de San Agustin, que desgraciadamente es de procedencia incierta y, por tanto, no es nada claro saber a qué templo se refería.

${ }_{59}$ P. de Palol, op. cit. (n. 4), 82-102 y especialmente, 83-86 y 98-99; M. Almagro y P. de Palol, op. cit. (n. 3), 33; idem. op. cit. (n. 2), 36 y 187; M. Oliva, Presencia de la Diputación de Gerona en Ampurias. Excavaciones en la basílica paleocristiana en el siglo xix. Hallazgos arqueológicos y descubrimiento del foro romano, Miscelánea Arqueológica. XXV Aniversario de los Cursos Internacionales de Prehistoria y Arqueología en Ampurias (1947-1971), Barcelona, 1974, vol. II, 89-90; S. Alavedra, op. cit. (n. 34), 115-118 (núm. 25); J. M. Nolla y N. M. Amich, op. cit. (n. 4).

${ }^{60}$ Sobre los sarcófagos; M. Almagro y P. de Palol, op. cit. (n. 3), 40; P. de Palol, op. cit. (n. 2), 37 y 317-318; M. Oliva, op. cit. (n. 59), 91; G. Fabre, M. Mayer e I. Rodà, op. cit. (n. 10), 157-158; J. M. Nolla y N. M. Amich, op. cit. (n. 4). Sobre el pie de altar: R. Marcet y E. Sanmarti, Empúries, Barcelona, 1989, 172-173; J. M. Nolla y N. M. Amich, op. cit. (n. 4), con paralelos en Narbona, Quintanilla de las Viñas, Toledo, Mérida, Mértola, entre otros, y con dataciones seguras en pleno siglo vil.

${ }^{6}$ El puerto principal hay que situarlo entre Sant Martí y la Neápolis y, probablemente, aprovechando, también, la desembocadura del Fluvià. Sin embargo el material cerámico denota que continuaban frecuentándose los puertos subsidiarios de Riells y la Clota, en la Escala (F. J. Nieto y J. M. Nolla, op. cit. (n. 24), 277-278 y 282-283). 


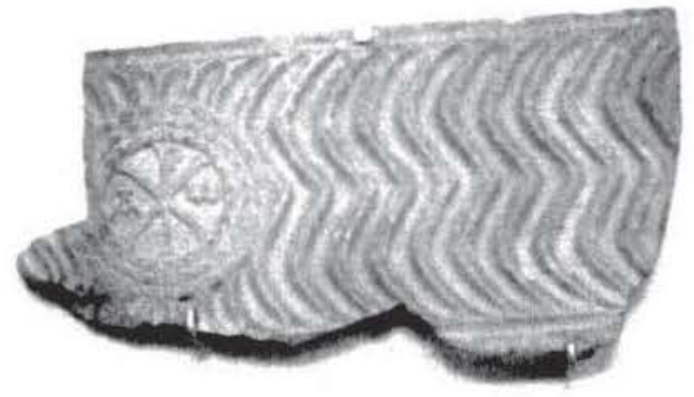

$\Lambda$

Figura 4. Sarcófagos decorados de taller aquitano. A) Hallado en los alrededores de Santa Margarida. B) Procedente de una de las masias del lugar de "Les Corts". (Ambos en el Museo Monográfico de Ampurias.)

de categoria regional, pero bien dotado y eficaz, perfectamente adecuado a la situación de equilibrio lograda después de la crisis urbana de los siglos I al ıl. ¿Pero qué documentos lo apoyan?

Para la Tardía Antigüedad nuestros datos son indirectos pero, creemos, dignos de tenerse en cuenta: la tradición, la espléndida situación en relación al territorio inmediato (valles del Fluvia y del Ter) y la propia importancia de una ciudad episcopal, con Gerunda, las principales, las únicas de este territorio. Además, los datos alto-medievales nos ofrecen una extraordinaria información donde el puerto es un elemento esencial a la vez que nos permiten observar otros detalles de origen mucho más antiguo que nos aleja, definitivamente, de las hipótesis tradicionales y que nos ayuda a entender mucho mejor el papel real de la ciudad de Ampurias no sólo en esta importante etapa sino en el periodo inmediatamente anterior. No en vano, los carolingios no dudarán ni un instante en convertir Ampurias en la capital de uno de los nuevos condados puesto que no cabia otra posibilidad ${ }^{22}$. En el 813 vemos a Irmingarius. conde de Ampurias, actuar hábilmente en acciones corsarias contra los sarracenos en las alejadas aguas de las Baleares ${ }^{63}$. En el 891, las naves del conde Sunniarius II atacan el puerto de Pechina, en la lejana Almeria, en una muestra más del interés por el mar y de la capacidad

6. Si bien parece indiscutible que el puerto de Rosas tiene ciertas ventajas en relación con el de Ampurias, es cierto también que éste es mucho más adecuado para relacionarse con el interior del pais y que después de las importantes obras de acondicionamiento de época tardorrepublicana es el primer puerto de este territorio hasta el siglo xi (véase: J. Ruiz de Arbulo, Emporion y Rhode. Dos asentamientos portuarios en el golfo de Roses, Arqueologia Espacial, 4. Coloquio sobre distribución y relaciones entre asentamientos, Teruel, 1984, 115-140).

61 "Marius de Corsica ad Hispaniam cum multa praeda redeuntibus Ermingarius comes Emporitanus in Maiorica insidias posuit et octo naves eorum cepit, in quibus quingentos et eo amplius Corsos captivos invenit", Anales Reales del año 813 (R. D’Abadal, op. cit. (n. 8), 215). Este dato junto con las noticias según las cuales los habitantes de las Baleares pidieron ayuda a Carlomagno contra las agresiones musulmanas, valoran notablemente la importancia de Ampurias en estos años como sede de las 

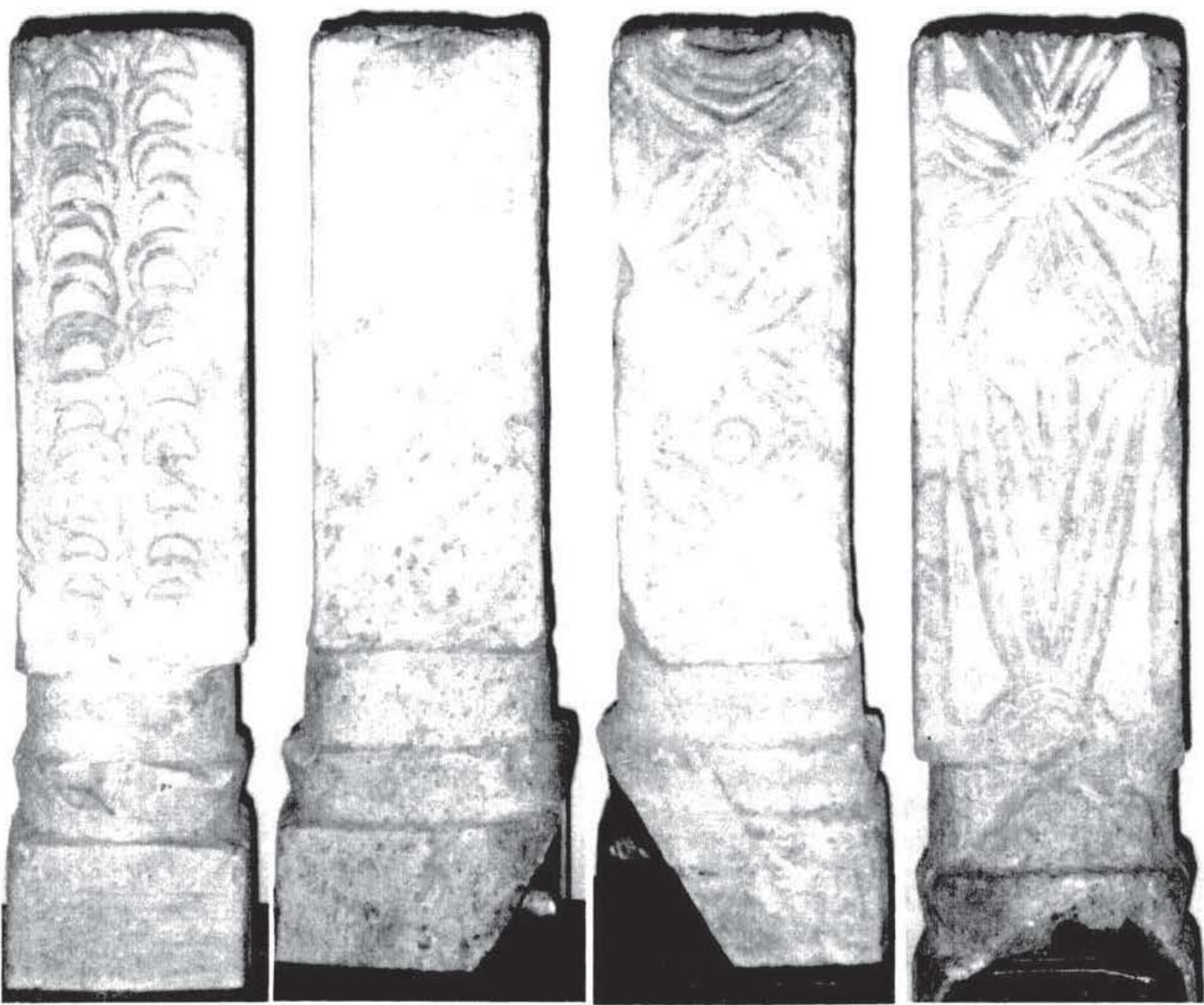

Figura 5,- Pie de altar de mármol (Museo Monográfico de Ampurias). A) Cara anterior. B) Cara posterior. () Cara lateral izquierda. D) Cara lateral derecha.

licrzas navales carolingias al sur del Cap de Creus, un papel que la ciudad mantendrá hasta. como ieremos, el siglo $x$. Consúltese en relación a esto: $\mathrm{R}$. d’Abadal, op. cit. (n. 8), 215 ( $\mathrm{A}$ nosaltres ens interessa especialment la noticia (se refiere a la actuación de Ermingarius o Irmingarius en Mallorca) perquè ens assabenta de com també el nostre litoral participava en operacions de neteja i de com era el comte d'Empúries i no el de Barcelona l'encarregat especial d'aquesta missió de defensa maritima. Potser aqui hauriem de veure-hi perquè la tradició de dicació marítima emporitana es continuarà - la tendència del comtat a mantenir-se amb personalitat pròpia deslligat de Barcelona, sota la influència de la qual cau aviat el comtat gironis) y $\mathbf{J}$. Amengual, Els origens del cristianisme a les Balears $i$ el seu desenvolupament fins a l'época musulmana, Mallorca, 1991, 453-460, 467-480 y 533 534. En la página 460 podemos leer: «El text no ens permet precisar tant, però si que fa versemblant que fos Empúries el lloc d'on s'originàs aquella expedició ja que era un punt que se significà damunt aquesta època i que el seu port podria haver concentrat les naus destinades a la defensa de la zona de la Septimània...” 
operativa de la escuadra ampuritana ${ }^{\text {th }}$. Son referencias indirectas que podrian ser discutidas y poco valoradas, como asi ha pasado a menudo. Otro dato, sin embargo, permite considerarlas adecuadamente a la vez que proyecta una luz distinta sobre la historia de la ciudad mucho más en consonancia con las ideas que aqui hemos apuntado. En efecto, en el año 933, siendo conde Gausfredo, hijo de Gausberto, tal como informa el historiador árabe ibn-Hayyan, por orden del califa cordobés, el general Abd al-Malik ibn Said ibn Abi Hammama al mando de fuerzas regulares y suficientes dirigió un ataque contra Ampurias que muy probablemente tenía como objetivo quebrar su poder naval y su actividad pirática sobre los territorios dependientes del califato: "La escuadra se presentó ante la ciudad de Ampurias, centro de sus atarazanas y refugio de sus naves. Los musulmanes la asediaron por tierra y por mar, quemaron las naves en el puerto y los arrabales y mataron a todos los que hallaron. Los muertos fueron más de cuatrocientos. Los habitantes de alrededor de la ciudad y las gentes de los castillos cercanos, cuando supieron del ataque de esta escuadra a la ciudad, entraron en ella para defenderla.» Después de cuatro días de sitio y destrucción, el ejército expedicionario, cumplidos los objetivos principales, se retiró sin haber logrado tomar por asalto Ampurias ${ }^{65}$.

Lejos de entrever una ciudad fantasma nos hallamos ante un centro activo, con unas dársenas, con un puerto donde fondean numerosas naves, sólidamente fortificado, y con una amplia población dispersa alrededor del núcleo principal, tal como hemos podido comprobar que sucedía en la Tardía Antigüedad. La potencia de las murallas bajo-imperiales aseguró la defensa si bien es muy posible que la expedición de Abd al-Malik significara un fuerte golpe a la actividad marinera (y corsaria) de los condes de Ampurias que poco después trasladarán la capital a Castelló, menos expuesta a los peligros que llegan del mar.

${ }^{64}$ Según recuerda el historiador árabe Abenhayan. Véase el texto traducido y comentado en M. Almagro, op. cit. (n. 2), 132-133 o en J. M. Millàs Vallicrosa, Textos dels historiadors àrabs referents a la Catalunya carolingia, Barcelona, 1987, XXXIV-XXXV.

65 P. Balañà, Les destruccions de L'Empúries medieval i la capitalitat comtal, Annals de l'Institut d'Estudis Empordanesos, 15, 1981-1982, 125-135. Parece ser que quedaría el recuerdo de este feroz ataque en el Cartulario de Santa Maria de Rosas, actualmente perdido, que incluía un precepto real del 944 en el que se refería a un reciente golpe de mano de piratas "paganos» y donde se mencionaba el saqueo de la ciudad, la captura de muchos de sus habitantes y la huida, dejándolo todo, de los restantes (P. Negre, Castelló de Ampurias de villa rural a capital del condado de Ampurias. Notas históricas (siglos IX a XII), Anales del Instituto de Estudios Gerundenses, 12, 1958, 100-101. 